Check for updates

Cite this: Chem. Commun., 2021, 57, 1141

Received 5th October 2020

Accepted 24th November 2020

DOI: $10.1039 / \mathrm{d} 0 \mathrm{cc} 06638 \mathrm{a}$

rsc.li/chemcomm

\section{Poly(dimethylsiloxane) and oligo(dimethylsiloxane) solvent effects on aromatic donor-acceptor interactions $\dagger$}

\author{
Shogo Amemori, (D) *abc Kyoka Kikuchi ${ }^{d}$ and Motohiro Mizuno (D) *abc
}

\begin{abstract}
Solvents with a wide range of polarities, including poly(dimethylsiloxane) and oligo(dimethylsiloxane), were used to evaluate aromatic donor-acceptor interactions between pyrene and pyromellitic diimide derivatives. The donor-acceptor interactions were stronger in siloxane solvents than in aliphatic solvents, possibly because of the poor solubility of the aromatics in siloxanes.
\end{abstract}

Aromatic donor-acceptor (D-A) interactions between electron-rich (donor) and electron-deficient (acceptor) aromatic molecules have been widely used as a driving force for the construction of supramolecular architectures ${ }^{1-5}$ such as capsules, ${ }^{2}$ liquid crystals, ${ }^{3}$ gels, ${ }^{4}$ and supramolecular polymers. ${ }^{5}$ The strength of the D-A interactions determines the properties of the supramolecular architecture, including stability, stimuli-sensitiveness, and self-repairing. Thus, it is crucial to understand and precisely control the structural and solvent dependence of D-A interactions.

Aromatic D-A interactions in the ground state and the $\pi-\pi$ interactions between aromatic molecules are generally contributed by electrostatic, dispersion, and charge-transfer interactions, as well as solvophobic effects. ${ }^{6}$ Although the complex contributions make it difficult to strictly interpret the solvent effects on D-A interactions, the effects can be roughly divided by polar and non-polar solvent systems. In a polar solvent system such as water or methanol, the $\mathrm{D}-\mathrm{A}$ interaction is mainly dominated by the hydrophobic effect, and thus more polar solvents give rise to higher association constants. ${ }^{7}$ Alternatively, in a non-polar solvent system, the lower polarity

\footnotetext{
${ }^{a}$ NanoMaterials Research Institute, Kanazawa University, Kanazawa 920-1192, Japan.E-mail: amemori@staff.kanazawa-u.ac.jp, mizuno@se.kanazawa-u.ac.jp

${ }^{b}$ Graduate School of Natural Science and Technology, Kanazawa University, Kanazawa 920-1192, Japan

${ }^{c}$ Institute for Frontier Science Initiative, Kanazawa University, Kanazawa 920-1192, Japan

${ }^{d}$ School of Chemistry, College of Science and Engineering, Kanazawa University, Kanazawa 920-1192, Japan

$\dagger$ Electronic supplementary information (ESI) available: ${ }^{1} \mathrm{H}{ }^{13} \mathrm{C}$ NMR HRMS data, curve fitting data for association constant, solubility test. See DOI: 10.1039/ d0cc06638a
}

enables stronger D-A interactions. ${ }^{8}$ For example, the association constants between 1,3,5-trinitrobenzene and naphthalene in non-polar solvents are in the order $n$-heptane $\left(9.58 \mathrm{M}^{-1}\right)$, $\mathrm{CCl}_{4}\left(5.16 \mathrm{M}^{-1}\right), \mathrm{CS}_{2}\left(3.25 \mathrm{M}^{-1}\right)$, and $\mathrm{CHCl}_{3}\left(1.82 \mathrm{M}^{-1}\right) .{ }^{8 a}$

Generally, the effects of low polarity solvents are interpreted as a result of their low dielectric constant facilitating electrostatic interaction between aromatic molecules. ${ }^{1 a, 8 c}$ In addition, the weak interactions ${ }^{6 d}$ between solvent molecules and solute molecules or the solvophobic effect ${ }^{8 d}$ in non-polar solvents contribute to an increase in the association constant between the solutes. However, the lowest polarity solvents to be evaluated for the solvent effect have been limited to aliphatic solvents such as $n$-hexane, $n$-heptane, and cyclohexane. It remains unclear whether the solvent effect is applicable to low-polarity solvents other than aliphatic solvents, such as poly(dimethylsiloxane) (PDMS) and oligo(dimethylsiloxane) (ODMS), nor is it clear what governs the D-A interactions in non-polar environments. Nevertheless, supramolecular architectures in non-polar solvents have been frequently constructed on the basis of $\mathrm{D}-\mathrm{A}$ interactions.

Here, we report the association constants between pyromellitic diimide (PMDI) derivatives (PMDIC6 and PMDISi) as acceptors and pyrene (Py) derivatives (PyC6 and PySi) as donors (Fig. 1) and determine the significant effect of the incompatibility between the solute and solvents on the stabilization of the D-A complexes by using PDMS and ODMS as solvents. PDMS and ODMS both have a flexible backbone of $\mathrm{Si}-\mathrm{O}$ bonds, which impart ionic properties, covered entirely with non-polar methyl groups. Their particular structure results in a weak intermolecular force (dispersion force) among the PDMS and ODMS molecules, leading to their low

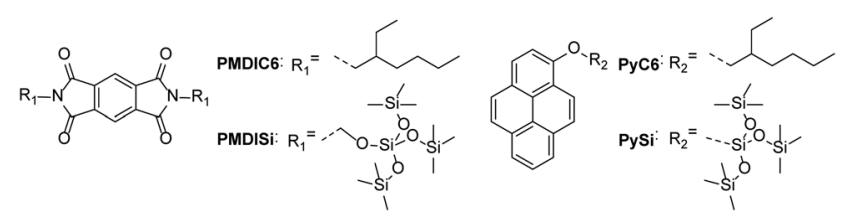

Fig. 1 Molecular structures of PMDIC6 and PMDISi acceptors and PyC6 and PySi donors. 
surface energy, poor solvation ability, and low solubility parameters. ${ }^{9-12}$ The outstanding "non-polar" nature of PDMS and ODMS leads to their usefulness in applications such as crystallization solvents ${ }^{10}$ and building units that facilitate phase segregation for liquid crystals ${ }^{11}$ and block co-polymers. ${ }^{12}$ Determining the solvent effect of siloxanes will elucidate the complex nature of the aromatic $\mathrm{D}-\mathrm{A}$ interactions in non-polar environments as well as aid in the rational design of supramolecular architectures using PDMS and ODMS.

First, we prepared PMDIC6 and PyC6, which are PMDI and Py attached to alkyl chains as solubilizing groups, by means of one-step processes (see the ESI $\dagger$ ). This resulted in adequate solubility of PMDIC6 and PyC6 in solvents having a wide range of polarities, such as PDMS and methanol. We used two PDMSs (PDMS(2000) with an average molecular weight of $2000 \mathrm{~g} \mathrm{~mol}^{-1}$ and PDMS(28000) with an average molecular weight of $28000 \mathrm{~g} \mathrm{~mol}^{-1}$ ) and four ODMSs (Fig. 2a) to investigate the solvent effect. Although PMDIC6 and PyC6 exhibit considerably low absorption in the visible region, mixing the compounds induced a new absorption band originating from a chargetransfer absorption with a charge-transfer emission (Fig. 2b). The absorbance of the charge-transfer absorption strongly depended on the solvents (Fig. 2c). The time-dependence of the charge-transfer absorption of PyC6-PMDIC6 was measured in $n$-hexane and PDMS(28 000) with varying temperatures. Both systems showed remarkable stability and a quick response $(<5 \mathrm{~min})$ of the charge-transfer absorption to the change in the temperature, indicating a rapid shift of equilibrium even in PDMS(28 000), which has a high viscosity (Fig. S1, ESI $\dagger$ ). The association constants between PMDIC6 and PyC6 were evaluated from the charge-transfer absorption in the visible region by using nonlinear curve fitting with a 1:1 binding model (eqn S1 and Fig. S4-S36, ESI †). The observed data in all solvents fit the 1:1 model well within the concentration range that we used, supporting the premise that dimerization between the donors and acceptors predominated, although there might be minor polymeric species such as $2: 2$ and $1: 2$ complexes.

The evaluated association constant $K_{\mathrm{a}}$ and the standard Gibbs free energy of formation $\Delta G^{\circ}$ between PMDIC6 and PyC6 in the solvents are listed in Table 1. In order to recognize the association behavior of the PMDIC6-PyC6 pair, the values of $-\Delta G^{\circ}$ in the typically used solvents were plotted as a function of the relative permittivity $\varepsilon_{\mathrm{r}}{ }^{13}$ and $E_{\mathrm{T}}(30)$, which are representative empirical solvent polarity scales derived from the solvatochromism of pyridinium $N$-phenolate betaine dyes (Fig. $2 \mathrm{~d}$ and e). ${ }^{14}$ The solvent effects were divided into non-polar and polar regions by using chloroform and acetone as the boundary, which is consistent with the reported propensity as discussed above.

In the polar solvents, $-\Delta G^{\circ}$ increased roughly with an increase in $E_{\mathrm{T}}(30)$ (Fig. 2d), although there was no correlation of $-\Delta G^{\circ}$ with the relative permittivity (Fig. 2e). These behaviors were interpreted as the hydrophobic effect playing a key role in the D-A aromatic interaction rather the electrostatic interaction. ${ }^{6 c, 7}$ If the electrostatic force dominates, in the solvents with a high dielectric constant, the binding energy should decrease as the electrostatic force decreases. In the non-polar solvent region, the archetypal

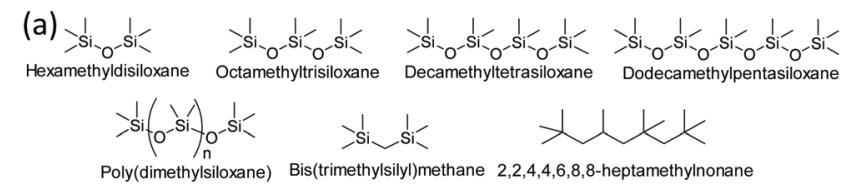

(b)

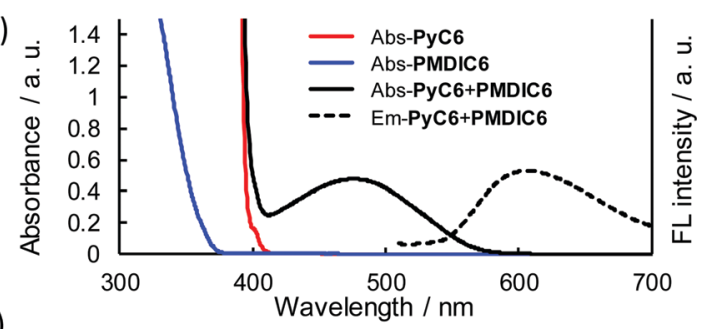

(c)
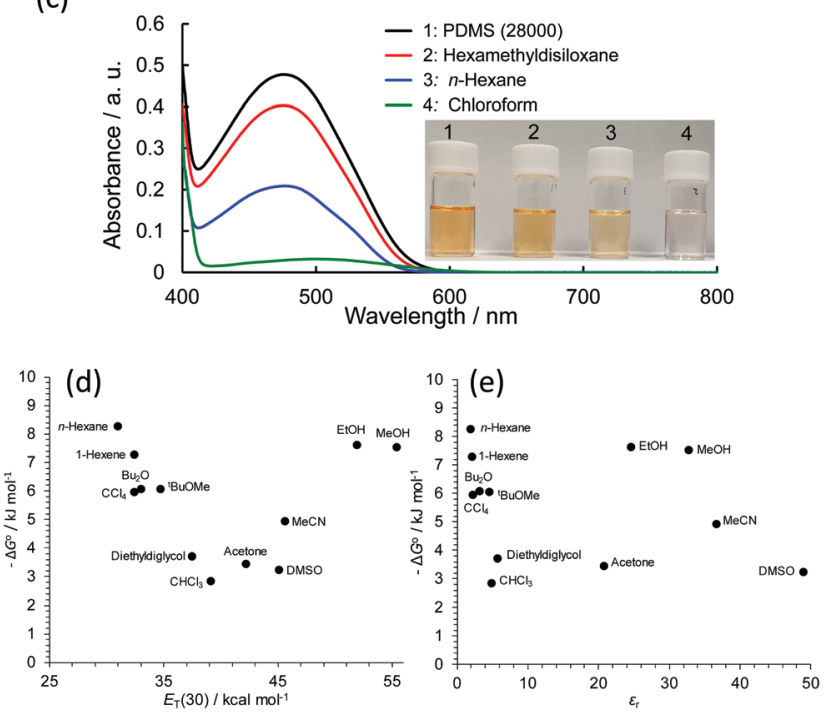

Fig. 2 (a) Molecular structure of ODMS, PDMS, bis(trimethylsilyl)methane, and 2,2,4,4,6,8,8-heptamethylnonane. (b) Absorption spectra of PyC6, PMDIC6 and PyC6-PMDIC6, and the emission spectrum $\left(\lambda_{\mathrm{ex}}=460 \mathrm{~nm}\right)$ of PyC6-PMDIC6 in PDMS(28 000) ([PyC6] $=11 \mathrm{mM}$, [PMDIC6] $=2 \mathrm{mM}$ ). (c) Absorption spectra and photographs of PyC6-PMDIC6 in PDMS(28 000), hexamethyldisiloxane, $n$-hexane and chloroform ([PyC6] $=11 \mathrm{mM}$, [PMDIC6] $=2 \mathrm{mM}, 25^{\circ} \mathrm{C}$ ). Plot of $-\Delta G^{\circ}$ vs. (d) Solvent polarity parameter $E_{\mathrm{T}}(30)$ and (e) the relative permittivity $\varepsilon_{\mathrm{r}}$, for the association constant of the PMDIC6-PyC6 pair.

trend observed was an increase in the association constants with both decreasing $E_{\mathrm{T}}(30)$ and decreasing $\varepsilon_{\mathrm{r}}$ of the solvents (Fig. 2d and e). ${ }^{6,8}$ The typical D-A interaction properties of the PMDIC6PyC6 pair encouraged us to further investigate the solvent effects of PDMS and ODMS using this pair.

Although empirical $E_{\mathrm{T}}(30)$ solvent scales for PDMSs and ODMSs have not been reported, their solvent polarity is similar to that derived from other empirical solvent polarity parameters such as the Kamlet-Taft polarity parameters for alkanes. ${ }^{10 b, 15}$ Bis(trimethylsilyl)methane and the branched alkane heptamethylnonane were used to evaluate the structural effects of the solvents on the D-A interaction (Fig. 2a). The association constants and $-\Delta G^{\circ}$ of the siloxanes gradually increased as their molecular weight increased, although there appeared to be a plateau. The association constant for PDMS(28 000) was 5 times higher than that of $n$-hexane and 40 times higher than that of chloroform, which had the lowest association constant in this experiment. This is the first report on the solvent effects 
Table 1 Association constants and standard Gibbs free energy of formation between PMDIC6 and PyC6 in various solvents at $25^{\circ} \mathrm{C}$

\begin{tabular}{|c|c|c|c|c|}
\hline Solvent & $\begin{array}{l}K_{\mathrm{a}} \\
\left(\mathbf{M}^{-1}\right)^{a b}\end{array}$ & $\begin{array}{l}-\Delta G^{\circ} \\
\left(\mathrm{kJ} \mathrm{mol}{ }^{-1}\right)\end{array}$ & $\varepsilon_{\mathrm{r}}$ & $\begin{array}{l}E_{\mathrm{T}}(30) \\
\left(\mathrm{kcal} \mathrm{mol}^{-1}\right)\end{array}$ \\
\hline Methanol & $21(0.2)$ & 7.5 & $33^{c}$ & $55.4^{h}$ \\
\hline Ethanol & $22(0.3)$ & 7.6 & $25^{c}$ & $51.9^{h}$ \\
\hline Acetonitrile & $7.3(0.1)$ & 4.9 & $37^{c}$ & $45.6^{h}$ \\
\hline DMSO & $3.7(0.2)$ & 3.2 & $47^{c}$ & $45.1^{h}$ \\
\hline Acetone & $4.1(0.2)$ & 3.5 & $21^{c}$ & $42.2^{h}$ \\
\hline Chloroform & $3.2(0.04)$ & 2.9 & $4.8^{c}$ & $39.1^{h}$ \\
\hline Diethyldiglycol & $4.5(0.06)$ & 3.7 & $5.7^{d}$ & $37.5^{h}$ \\
\hline tert-Butylmethyl ether & $12(0.2)$ & 6.1 & $4.5^{e}$ & $34.7^{h}$ \\
\hline Di- $n$-butyl ether & $12(0.1)$ & 6.1 & $3.1^{c}$ & $33.0^{h}$ \\
\hline Tetrachloromethane & $11(0.3)$ & 6.0 & $2.2^{c}$ & $32.4^{h}$ \\
\hline 1-Hexene & $19(0.4)$ & 7.3 & $2.1^{c}$ & $32.4^{h}$ \\
\hline$n$-Hexane & $28(0.4)$ & 8.3 & $1.9^{c}$ & $31.0^{h}$ \\
\hline Hexamethyldisiloxane & $88(1.1)$ & 11.1 & $2.2^{f}$ & - \\
\hline Octamethyltrisiloxane & $95(1.3)$ & 11.3 & $2.3^{f}$ & - \\
\hline Decamethyltetrasiloxane & $110(1.8)$ & 11.6 & $2.4^{f}$ & - \\
\hline Dodecamethylpentasiloxane & $110(2.0)$ & 11.6 & $2.5^{f}$ & - \\
\hline $\begin{array}{l}\text { Poly(dimethylsiloxane) } \\
\left(M_{\mathrm{n}} 2000 \mathrm{~g} \mathrm{~mol}^{-1}\right)\end{array}$ & $130(1.4)$ & 12.1 & $2.7^{f}$ & - \\
\hline $\begin{array}{l}\text { Poly(dimethylsiloxane) } \\
\left(M_{\mathrm{n}} 28000 \mathrm{~g} \mathrm{~mol}^{-1}\right)\end{array}$ & $140(3.5)$ & 12.2 & $2.8^{f}$ & - \\
\hline $\begin{array}{l}2,2,4,4,6,8,8- \\
\text { Heptamethylnonane }\end{array}$ & $30(0.3)$ & 8.4 & - & - \\
\hline Bis(trimethylsilyl)methane & $45(0.2)$ & 9.4 & $2.1^{g}$ & - \\
\hline
\end{tabular}

${ }^{a}$ Association constants in all solvents were calculated by using nonlinear least squares curve fitting a $1: 1$ binding model. ${ }^{b}$ Standard error for non-linear least squares in parentheses. ${ }^{c}$ Data from ref. $13 a .{ }^{d}$ Data from ref. $13 b .{ }^{e}$ Data from ref. $13 c .{ }^{f}$ Data from ref. $13 d .{ }^{g}$ Data from ref. $13 e .{ }^{h}$ Data from ref. 14.

of PDMS and ODMS promoting the formation of aromatic D-A complexes. Because the association constant of $2,2,4,4,6,8$, 8-heptamethylnonane with branched methyl moieties was comparable to that of $n$-hexane, the higher association constants of the ODMSs were not attributable to the differences in the molecular size and the methyl moieties between $n$-hexane and the ODMSs.

Considering that the relative permittivity and empirical solvent polarity parameters of the siloxanes and $n$-hexane are much the same, electrostatic forces are not sufficient to explain the high association constants of the siloxane solvents. To obtain further information, we evaluated the solubility of PyC6 and PMDIC6 in $n$-hexane, PDMSs, and ODMSs (Table S1, ESI $\dagger$ ). The higher molecular weight siloxanes showed lower solubility of PyC6 and PMDIC6, and all the siloxanes were poor solvents for the dyes compared with $n$-hexane. The intermolecular forces of PDMS and ODMS, which are mainly governed by the dispersion force, are weaker than those of alkanes. ${ }^{9 b}$ Although consideration of the interaction between the aromatic molecules and the solvent molecules from the solubility test is difficult because of their different molecular sizes and entropy of mixing, the low solubility of PyC6 and PMDIC6 in the siloxanes suggests that PDMSs and ODMSs could not inhibit the self-aggregation of the aromatics that was driven by the dispersion force, indicating an incompatibility between the aromatic molecules and the siloxane solvents. In fact, block co-polymers of poly(dimethylsiloxane) and polystyrene, which have an aromatic moiety, are well-known to phase separate into nanoscale morphologies owing to their incompatibility. ${ }^{12 a, 12 d}$ As the solubility trend was consistent with that of the association constants between PyC6 and PMDIC6, the incompatibility of the siloxanes to the aromatics could accelerate the $\mathrm{D}-\mathrm{A}$ interactions as well as the self-aggregation.

Bis(trimethylsilyl)methane has a higher surface tension (19.1 $\mathrm{mN} \mathrm{m}^{-1}$ ) than hexamethyldisiloxane $\left(16.2 \mathrm{mN} \mathrm{m}^{-1}\right)$, implying that an increase in the intermolecular force is observed upon replacing the $\mathrm{Si}-\mathrm{O}-\mathrm{Si}$ bond with a $\mathrm{Si}-\mathrm{C}-\mathrm{Si}$ bond. ${ }^{16}$ As expected, a lower association constant between PyC6 and PMDIC6 was observed in bis(trimethylsilyl)methane $\left(45 \mathrm{M}^{-1}\right)$ compared to that in hexamethyldisiloxane $\left(88 \mathrm{M}^{-1}\right)$. In addition, bis(trimethylsilyl)methane was a good solvent for PyC6 and PMDIC6 compared with hexamethyldisiloxane (Table S1, ESI $\dagger$ ). This result supports the hypothesis that the incompatibility between the aromatic and siloxane molecules induces higher association constants. It can be noted that the surface tension is not directly correlated with the association constant owing to the molecular weight dependence of the surface tension. ${ }^{9 b}$

To evaluate the effect of the side chains, PMDISi and PySi with a tris(trimethylsilyloxy)silyl moiety were synthesized (Fig. 1). The charge-transfer absorption of the PMDISi-PySi pair showed significant stability and depended on the solvents similar to the PMDIC6-PyC6 pair (Fig. S2 and S3, ESI $\dagger$ ). The solubility test clearly showed higher solubility of PMDISi and PySi compared with PMDIC6 and PyC6, indicating the high compatibility of the tris(trimethylsilyloxy)silyl moiety with PDMSs and ODMSs (Table S1, ESI $\dagger$ ). Nevertheless, the association constants between PMDISi and PySi in siloxanes were three to five times higher than those in $n$-hexane (Table 2). This difference is consistent with the solvent effect of the media for the PMDIC6-PyC6 pairs. Remarkably, the solvent effects for the association constants of the PMDIC6-PySi and PMDISi-PyC6 pairs were almost identical to those of the PMDIC6-PyC6 and PMDISi-PySi pairs, although the association constants in the same solvents depended on the combination of the donor and the acceptor (Table S2, ESI $\dagger$ ). The dependence of the association constant on the D-A combination may be attributed to the geometric preference for stacking between the aromatic cores as a result of the steric hindrance of the side chains, or to the difference in the electrostatic properties of the aromatic cores by the side chains. It is significant that the side chains affected

Table 2 Association constants and the Gibbs free energy of formation between PMDISi and PySi in $n$-hexane, PDMSs and ODMSs at $25^{\circ} \mathrm{C}$

\begin{tabular}{llr}
\hline Solvent & $K_{\mathrm{a}}\left(\mathrm{M}^{-1}\right)^{a b}$ & $-\Delta G^{\circ}\left(\mathrm{kJ} \mathrm{mol}^{-1}\right)$ \\
\hline$n$-Hexane & $23(0.3)$ & 7.8 \\
Hexamethyldisiloxane & $72(0.9)$ & 10.6 \\
Octamethyltrisiloxane & $81(1.8)$ & 10.9 \\
Decamethyltetrasiloxane & $91(0.8)$ & 11.2 \\
Dodecamethylpentasiloxane & $96(0.9)$ & 11.3 \\
Poly(dimethylsiloxane) $\left(M_{\mathrm{n}} 2000 \mathrm{~g} \mathrm{~mol}^{-1}\right)$ & $130(1.4)$ & 12.1 \\
Poly(dimethylsiloxane) $\left(M_{\mathrm{n}} 28000 \mathrm{~g} \mathrm{~mol}^{-1}\right)$ & $140(3.9)$ & 12.3
\end{tabular}

${ }^{a}$ Association constants were calculated by using non-linear least squares curve fitting a 1:1 binding model. ${ }^{b}$ Standard error for nonlinear least squares in parentheses. 
the association constants but not the solvent effect of the siloxanes. These findings show the generality of the solvent effect and the crucial role of the incompatibility between the solvent and the aromatic core rather than the side chains for the solvent effect.

In conclusion, we demonstrated the solvent effects of PDMS and ODMS on aromatic $\mathrm{D}-\mathrm{A}$ interactions by evaluating the association constants between PMDI and Py derivatives in various solvents. The siloxanes induced higher association constants in non-polar environments. The solvent effect may originate from the incompatibility between the aromatic cores and the siloxane molecules owing to the weak dispersion force. Recently, there has been a debate on the exact mechanism of the interaction between aromatic molecules. ${ }^{6 f}$ These findings may help elucidate the origin of aromatic D-A interactions and $\pi-\pi$ interactions. The cause of the solvent effect of the siloxanes on the D-A interaction requires further investigation using various donor and acceptor molecules.

This work was supported by JSPS KAKENHI Grants 18K14187 (Early-Career Scientists).

\section{Conflicts of interest}

There are no conflicts to declare.

\section{Notes and references}

1 (a) A. Das and S. Ghosh, Angew. Chem., Int. Ed., 2014, 53, 2038-2054; (b) M. Kumar, K. V. Rao and S. J. George, Phys. Chem. Chem. Phys., 2014, 16, 1300-1313; (c) H. Kar and S. Ghosh, Isr. J. Chem., 2019, 59, 881-891.

2 (a) C. Wang, S. Yin, S. Chen, H. Xu, Z. Wang and X. Zhang, Angew. Chem., Int. Ed., 2008, 47, 9049-9052; (b) C. Wang, Y. Guo, Y. Wang, $\mathrm{H}$. Xu and X. Zhang, Chem. Commun., 2009, 5380-5382; (c) S. Chakraborty, D. Ray, V. K. Aswal and S. Ghosh, Chem. - Eur. J., 2018, 24, 16379-16387.

3 (a) V. Percec, M. Glodde, T. K. Bera, Y. Miura, I. Shiyanovskaya, K. D. Singer, V. S. K. Balagurusamy, P. A. Heiney, I. Schnell, A. Rapp, H. W. Spiess, S. D. Hudsonk and H. Duan, Nature, 2002, 417, 384-387; (b) K. R. Leight, B. E. Esarey, A. E. Murray and J. J. Reczek, Chem. Mater., 2012, 24, 3318-3328; (c) M. V. Winkle, D. A. Scrymgeour, B. Kaehr and J. J. Reczek, Adv. Mater., 2018, 30, 1706787.

4 (a) T. Yuan, M. Vazquez, A. N. Goldner, Y. Xu, R. Contrucci, M. A. Firestone, M. A. Olson and L. Fang, Adv. Funct. Mater., 2016, 26, 8604-8612; (b) C. Li, C. Shen, J. Nie and H. Qiu, Chem. - Asian J., 2018, 13, 1678-1682; (c) J. Han, D. Yang, X. Jin, Y. Jiang, M. Liu and P. Duan, Angew. Chem., Int. Ed., 2019, 58, 7013-7019.

5 (a) S. Burattini, B. W. Greenland, D. H. Merino, W. Weng, J. Seppala, H. M. Colquhoun, W. Hayes, M. E. MacKay, I. W. Hamley and S. J. Rowan, J. Am. Chem. Soc., 2010, 132, 12051-12058; (b) T. Haino, A. Watanabe, T. Hirao and T. Ikeda, Angew. Chem., Int. Ed., 2012, 51, 1473-1476; (c) Y. Han, Y. Tian, Z. Li and F. Wang, Chem. Soc. Rev., 2018, 47, 5165-5176; (d) K. Jalani, A. D. Das, R. Sasmal, S. S. Agasti and S. J. George, Nat. Commun., 2020, 11, 1-9.
6 (a) C. A. Hunter and J. K. M. Sanders, J. Am. Chem. Soc., 1990, 112, 5525-5534; $(b)$ Z. Chen, A. Lohr, C. R. Saha-Möller and F. Würthner, Chem. Soc. Rev., 2009, 38, 564-584; (c) C. R. Martinez and B. L. Iverson, Chem. Sci., 2012, 3, 2191-2201; (d) Z. Chen, B. Fimmel and F. Würthner, Org. Biomol. Chem., 2012, 10, 5845-5855; (e) R. Thakuria, N. K. Nath and B. K. Saha, Cryst. Growth Des., 2019, 19, 523-528; $(f)$ K. Carter-Fenk and J. M. Herbert, Chem. Sci., 2020, 6758-6765.

7 M. S. Cubberley and B. L. Iverson, J. Am. Chem. Soc., 2001, 123, 7560-7563.

8 (a) C. C. Thompson and P. A. D. de Maine, J. Am. Chem. Soc., 1963, 85, 3096-3101; (b) C. C. Thompson and P. A. D. De Maine, J. Phys. Chem., 1965, 69, 2766-2771; (c) R. Foster, Organic Charge-Transfer Complexes, Academic Press Inc., London, 1969; (d) G. M. Prentice, S. I. Pascu, S. V. Filip, K. R. West and G. D. Pantoş, Chem. Commun., 2015, 51, 8265-8268; (e) V. C. Wakchaure, L. V. Pillai, G. Goudappagouda, K. C. Ranjeesh, S. Chakrabarty, S. Ravindranathan, P. R. Rajamohanan and S. S. Babu, Chem. Commun., 2019, 55, 9371-9374.

9 (a) E. L. Warrick, M. J. Hunter and A. J. Barry, Ind. Eng. Chem., 1952, 44, 2196-2202; (b) M. J. Owen, Ind. Eng. Chem. Prod. Res. Dev., 1980, 19, 97-103; (c) C. Rücker and K. Kümmerer, Chem. Rev., 2015, 115, 466-524.

10 (a) W. H. Monillas, J. F. Young, G. P. A. Yap and K. H. Theopold, Dalton Trans., 2013, 42, 9198-9210; (b) M. A. Ab Rani, N. Borduas, V. Colquhoun, R. Hanley, H. Johnson, S. Larger, P. D. Lickiss, V. Llopis-Mestre, S. Luu, M. Mogstad, P. Oczipka, J. R. Sherwood, T. Welton and J. Y. Xing, Green Chem., 2014, 16, 1282-1296; (c) K. E. Aldrich and A. L. Odom, Chem. Commun., 2019, 55, 4403-4406.

11 (a) C. A. Vieth, E. T. Samulski and N. Sanjeeva Murthy, Liq. Cryst., 1995, 19, 557-563; (b) R. H. Zha, B. F. M. De Waal, M. Lutz, A. J. P. Teunissen and E. W. Meijer, J. Am. Chem. Soc., 2016, 138, 5693-5698; (c) A. Kawafuchi, S. Kutsumizu, Y. Kawase, I. Tokiwa, T. Udagawa and Y. Miwa, Phys. Chem. Chem. Phys., 2020, 22, 10132-10141.

12 (a) Y. S. Jung and C. A. Ross, Nano Lett., 2007, 7, 2046-2050; (b) M. D. Rodwogin, C. S. Spanjers, C. Leighton and M. A. Hillmyer, ACS Nano, 2010, 4, 725-732; (c) B. Van Genabeek, B. F. M. De Waal, M. M. J. Gosens, L. M. Pitet, A. R. A. Palmans and E. W. Meijer, J. Am. Chem. Soc., 2016, 138, 4210-4218; (d) J. Garnier, J. Arias-Zapata, O. Marconot, S. Arnaud, S. Böhme, C. Girardot, D. Buttard and M. Zelsmann, ACS Appl. Mater. Interfaces, 2016, 8, 9954-9960; (e) J. A. Berrocal, R. H. Zha, B. F. M. D. Waal, J. A. M. Lugger, M. Lutz and E. W. Meijer, ACS Nano, 2017, 11, 3733-3741.

13 (a) D. R. Lide, CRC Handbook of Chemistry And Physics: A ReadyReference Book of Chemical And Physical Data, CRC Press, Boca Raton, FL, 90 ${ }^{\text {th }}$ edn, 2014; (b) F. Calderazzo and F. A. Cotton, Inorg. Chem., 1962, 1, 30-36; (c) I. M. Smallwood, Handbook of Organic Solvent Properties, Elsevier Ltd, 1996; (d) M. S. Beevers, S. J. Mumby, S. J. Clarson and J. A. Semlyen, Polymer, 1983, 24, 1565-1570; (e) R. A. Holroyd, K. Itoh and M. Nishikawa, Nucl. Instrum. Methods Phys. Res., Sect. A, 1997, 390, 233-236.

14 C. Reichardt, Chem. Rev., 1994, 94, 2319-2358.

15 J. E. Brady, D. Bjorkman, C. D. Herter and P. W. Carr, Anal. Chem., 1984, 56, 278-283.

16 (a) R. Wagner, L. Richter, Y. Wu, J. Weißmüller, J. Reiners, E. Hengge, A. Kleewein and K. Hassler, Appl. Organomet. Chem., 1997, 11, 645-657; (b) J. Tan, Y. Liu and Z. Ye, J. Mol. Liq., 2019, 279, 657-661. 